See discussions, stats, and author profiles for this publication at: https://www.researchgate.net/publication/331998270

\title{
Spatial Analysis and Heritage Conservation: Leveraging 3-D Data and GIS for Monitoring Earthen Architecture
}

Article in Journal of Cultural Heritage · March 2019

DOI: 10.1016/j.culher.2019.02.011

CITATIONS

7

3 authors:

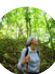

Arianna Campiani

Sapienza University of Rome

11 PUBLICATIONS 17 CITATIONS

SEE PROFILE

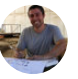

Nicola Lercari

University of California, Merced

53 PUBLICATIONS 362 CITATIONS

SEE PROFILE

Some of the authors of this publication are also working on these related projects:

Bodie 3-D Project View project

Project Catalhoyuk Research Project View project
READS

637

Aving Ashley Morgan Lingle

Cardiff University

11 PUBLICATIONS 16 CITATIONS

SEE PROFILE 
Campiani et al. 2019 - Author Version

\title{
The final publication is available via Elsevier at
}

https:// doi.org/ 10.1016/j.culher.2019.02.011.

Please cite as: Campiani, Arianna, Ashley M. Lingle, and Nicola Lercari. 2019. "Spatial Analysis and Heritage Conservation: Leveraging 3-D Data and GIS for Monitoring Earthen Architecture." J ournal of Cultural Heritage. https:// doi.org/ 10.1016/j.culher.2019.02.011.

Spatial Analysis and Heritage Conservation: Leveraging 3-D Data and GIS for Monitoring Earthen Architecture

Corresponding author: Arianna Campiani, Department of Anthropology and Heritage Studies, University of California, Merced Permanent address: 5200 North Lake Road, 95343, Merced, CA, USA (acampiani@ucmerced.edu)

Ashley Lingle, School of History, Archaeology and Religion, Cardiff University

Permanent address: John Percival Building, Colum Drive, Cardiff, CF10 3EU, UK

(ashlingle@gmail.com)

Nicola Lercari, Department of Anthropology and Heritage Studies, University of California, Merced

Permanent address: 5200 North Lake Road, 95343, Merced, CA, USA (nlercari@ucmerced.edu)

Length of Manuscript: 5,170 words (including keywords, acknowledgment and funding)

References: 1,794 words

\begin{abstract}
This paper discusses new advances in heritage site monitoring using a geo-spatial method for assessing the state of preservation of earthen architecture overtime as a preventive conservation measure. The proposed method leverages a comprehensive (quantitative-qualitative) approach that gathers multitemporal data including environmental information collected by means of environmental loggers, qualitative vulnerability assessment of mud-brick walls, and surface change detection information obtained by comparing terrestrial laser scanning point cloud capturing the decay of building's wall features over time. Producing a detailed spatial understanding of the conservation issues that affect mudbrick walls in large earthen sites, this method can be used by conservators to rapidly identify which buildings require immediate intervention and lay the basis for future evaluation of the conservation actions undertaken. To test the effectiveness of the proposed geospatial model in producing a comprehensive view of the environmental risk and pattern of decay that affect mudbrick structures, this paper presents analyses and results obtained in a six-year study at Çatalhöyük, Turkey. Our results
\end{abstract}


corroborate the effectiveness of the proposed method and prove that it can be successfully employed to create preventive conservation measures at other earthen sites inside and outside the Near East.

Keywords: GIS; earthen architecture conservation; Çatalhöyük; digital monitoring; environmental risk; point clouds comparison

\section{Introduction}

The fragile composition of earthen architecture sites presents many challenges for conservators. Immediately after excavation, surfaces are exposed to environmental agents and temperature fluctuations that change the equilibrium achieved with internment, leading to structural instability and other microscale pathologies, such as cracking, material loss, and surface delamination [1]. Due to its delicate nature, the study of earthen architecture has mostly focused on the analysis of the material's composition, on the evaluation of different conservation methods [2], [3], and on environmental stability as one of the keys to the preservation of earthen materials. Many studies have identified water and moisture as main agents of deterioration, as they promote the formation of soluble salts inside the mud-bricks, which are subject to a cyclic process of dissolving and recrystallization that induces stress and loss of cohesion in the materials $[4],[5]$.

At Çatalhöyük and other archaeological sites with earthen architecture, major damage to plaster wall surfaces have been observed immediately after or within a few days of excavation due to the rapid desiccation of features [6]. For this reason, it is important to establish in situ protective systems that allow the plaster to gradually reach a state of equilibrium with ambient conditions and a monitoring program to understand both the local environmental conditions and the presence of moisture in the walls and ground [6, p. 218]. Three-dimensional (3-D) documentation has become a common method in archaeological practice, implemented during excavations for in-field documentation but also for mapping purposes and damage assessment [7]-[12]. This method has been demonstrated to be extremely useful for assessing damage at endangered archaeological landscapes and sites [13]-[15]. 3-D documentation has less frequently been applied to the monitoring of ancient earthen architecture [16]-[19].

Since 2009, the Çatalhöyük Research Project adopted a 2-D GIS platform linked to a custom SQL database to handle the vast amount of data produced by the excavation process [20]-[22]. Building on previous experiments with laser scanning [23], in 2011, digital imagery techniques for the generation of 
3-D excavation replicas and laser scanner recording were employed at an intra-site level [24]. Some interesting efforts have been made to relate archaeological excavations and digital documentation with 3D GIS visualizations [25] and to simulate with virtual reality an archaeological excavation of Building 89 starting from the stratigraphic 3-D data collected in the field [26].

Despite these efforts to document comprehensively the site with both 2-D and 3-D data, the information related to the preservation of buildings and their architectural features only started to be recorded systematically in 2014 by the current Conservation Team. From 2012-2017, an interdisciplinary team from the University of California, Merced and Duke University digitally documented Çatalhöyük's earthen structures, using and testing the potential utility of Terrestrial Laser Scanning (TLS) for site conservation planning [27], [28]. In addition to 3-D data, conservators from Cardiff University assessed the state of preservation of the fragile earthen architecture of buildings located on the Çatalhöyük East Mound in 2015 and 2017. According to on-site observation, in 2014 conservator placed a total of eight TinyTag data loggers in specific areas of the site no longer undergoing excavation, eight loggers to record temperature and three to register humidity - the number and type of loggers was due to budgetary limitations. Leveraging 2-D and 3-D multi-temporal monitoring of the Çatalhöyük North Area, we assessed the progressive decay and erosion of buildings and identified the areas of most immediate risk of deterioration. Additionally, this data is used to look at the efficacy of conservation treatments, aiding in a move away from treatment strategies focused on polymerization and more toward earth-based repair strategies.

To manage, analyze, and visualize the heterogeneous quantitative and qualitative data collected at Çatalhöyük, the authors utilized 2-D spatial analytical tools available in the ESRI ArcGIS platform. This allowed us to spatially combine the qualitative conservation assessment with quantitative environmental data (temperature and humidity) and surface material loss data obtained by computing the difference of TLS point clouds of North Area features recorded at different times.

\section{Research aim}

By combining 3-D technology and GIS, we performed an assessment of the conservation issues that affect the architecture of Çatalhöyük North Area. Our study aims to develop a spatial analytical model able to provide the Çatalhöyük Conservation Team and other conservators facing similar problems with datadriven tools for planning future conservation interventions and developing best practices that can be applied in other earthen heritage sites and case studies. 


\section{Research Context}

Çatalhöyük is an exceptional archaeological settlement in terms of physical and temporal scale in both prehistoric and modern periods. The site is located on the southern edge of the Anatolian plateau of what is now the arid agricultural Konya Plain. Between 7,100 to 5,900 cal BCE, an estimated 3000-8000 people lived at Çatalhöyük in mud-brick houses that were elaborately overlaid by each successive generation [29], [30]. The building technique integrated large mud-brick with timber post and beams on a modular rectangular plan. Entrance to the dwellings happened from the flat roof made of reeds and earth and supported by wooden beams. The walls were generally plastered and often painted and sometimes decorated with plastered features. Multiple levels of plasters have been detected and documented with archaeological excavations, suggesting a constant maintenance of the surface by its inhabitants [6].

To mitigate the effects of the harsh continental climate of the Konya Plain on the mud-brick, a permanent shelter was built in 2002-2003 over the South Area, and in 2007-2008 over the North Area. While the single walled polycarbonate sheeting that covers the shelter's roof protects the structures laying underneath from wind and direct rain or snow, it does not provide adequate UV radiation protection and is environmentally unstable.

Our investigation focuses on the North Area of the site and, in particular, we have been directing the 3-D comparison on eight buildings within the shelter (Buildings 5, 48, 49, 55, 64, 82, 114, 119) that were identified as a priority by Lingle, Head of the Çatalhöyük Conservation Team. These specific buildings were selected because they were no longer undergoing active excavation. It is important to underline that North Area buildings were excavated in different field seasons spanning 1996 to 2017 and that wall features have been dug at different times, even within buildings. Therefore, the exposure of the mud-brick to environmental factors and other threats differs greatly within the North Area, sometimes significantly within the same building. Moreover, at least one-third of the features included in our analyses have been conserved previously using different physical conservation interventions with varying degrees of success.

Matero and Moss [6] describe the monitoring efforts, on-site conservation actions and laboratory test undertaken at Çatalhöyük while suggesting best practices to preserve the newly excavated buildings, among them Building 5. The conservators collected eleven samples from plastered walls at different height and depth and measured moisture content upon extraction and several days later. The results in all cases demonstrate that salt recrystallization sometimes occurs at the surface-substrate interface and is 
associated with deterioration including flaking, delamination, and detachment [6, pp. 220-221]. However, the shelter was constructed after the completion of Matero and Moss' study, thus changing the conditions originally assessed, chiefly temperature and humidity see also [31, p. 160].

Based on the framework of the Çatalhöyük Digital Preservation Project [27], we aim to explore the concurrent agents of deterioration while performing a quantitative assessment of the conservation issues that affect the architecture of the Çatalhöyük North Area.

\section{Material and Methods: a GIS environment and 3-D data comparison to understand the deterioration process and its causes}

The need for a thorough analysis of earthen architecture that takes into account several factors such as

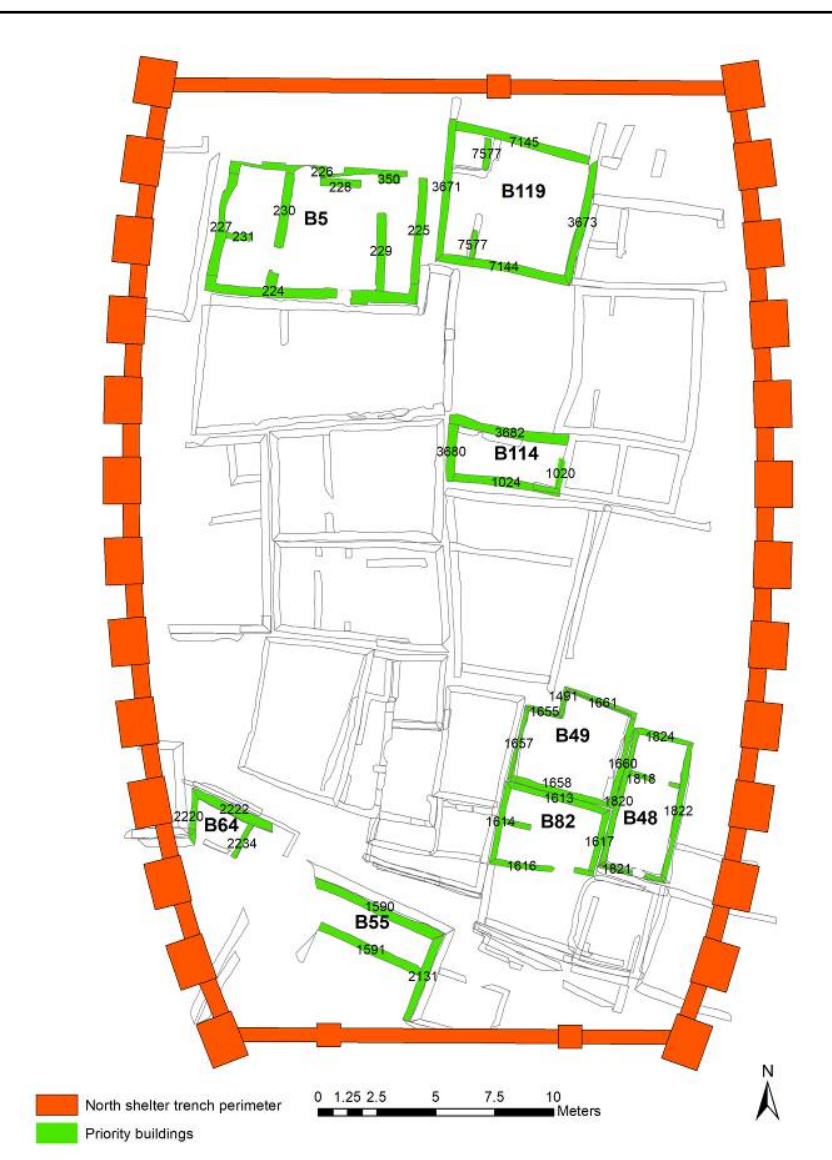

Fig 1. Map of the North Area. Priority buildings and their features are highlighted. environmental characteristics, material and building techniques, and the structural system of constructions has been discussed by several authors [4], [6], [16]. Following these recommendations in the understanding of the deterioration process experienced by mudbricks constructions at intra-site level, various techniques and approaches were combined. A GIS platform was used as an instrument for documentation and diagnosis purposes by analyzing newly collected environmental and architectural data.

In order to obtain spatial-temporary climate maps of temperature and humidity distribution under the shelter, and of the vulnerability of mud-bricks, we used Inverse Distance Weighted (IDW) interpolation technique. IDW is a deterministic interpolation method that estimates the value at unknown points using the sampled values and distance of surrounding nearby known points, without any statistical assumption abstracted from the dataset. Any point with an 
unknown value will be influenced by its known neighbors according to their distance [32]-[34]. We chose this method due to the limited number of available temperature and humidity stations in relation with the size of the North Shelter Area (about $973 \mathrm{~m}^{2}$ ). This methodology is employed by other works using the same distance-based method to estimate and calculate temperature variation [35]-[37], and evaluate the influence of environmental agents on heritage sites [38].

Because of the importance of 3-D data for conservation efforts [7], [11], [39]-[42] we performed surface change detection in the 3-D data collected from 2012-2017 using the Multiscale Model to Model Cloud Comparison (M3C2) method [43] in the open source software CloudCompare [44]. The results of this evaluation were later incorporated into the GIS and associated with the spatial analyses.

The North Area (Fig.1) was addressed using a deductive approach on different levels of analysis: the first is an area-wide anamnesis of the site — or search for significant data and information — to contextualize our observations thanks to the overview of the environmental and vulnerability data. The secondary level took into consideration the building characteristics such as depth, year of excavation, materials composition, orientation and relation with other architectural features. Finally, considering the material loss of walls through time.

\subsection{Environmental heritage risks map}


The temperature and humidity data recorded under the shelter every 15 and 30 minutes by TinyTag

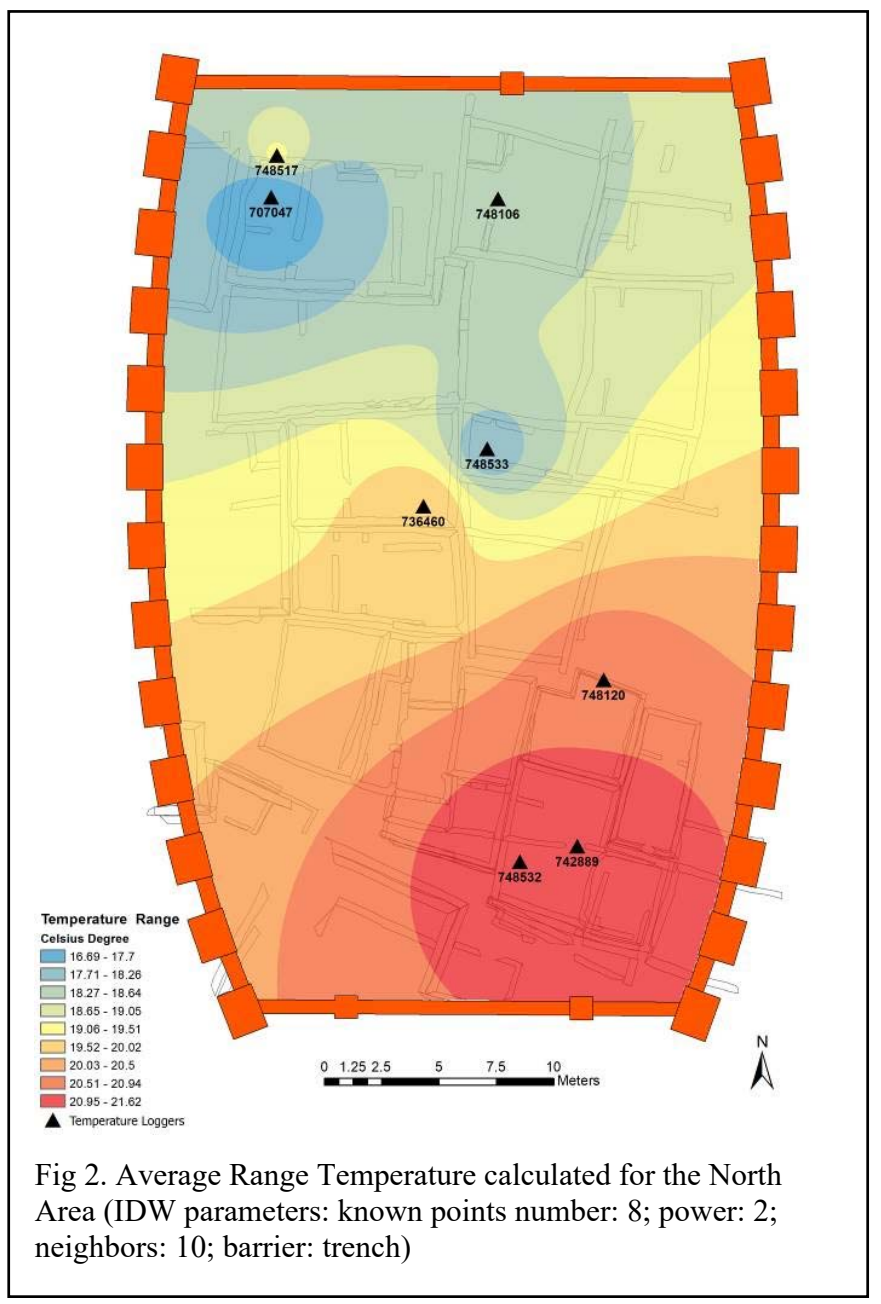

loggers in the North Area help understanding how dry/wet cycles and freeze/thaw cycles of water and moisture in the mud-brick cause surface material loss and erosion.

Our interest focuses on the temperature variation and thus, starting from the daily fluctuation range, we calculated the annual average thermal excursion value for the eight data loggers for August 2015-July 2016 (Fig. 2). The annual average temperature range calculated by the loggers is $19^{\circ} \mathrm{C}$, with the lowest monthly temperature recorded on January $3^{\text {rd }}, 2016$ of $-14^{\circ} \mathrm{C}$ and the highest monthly temperature recorded on July 31", 2016 of $52^{\circ} \mathrm{C}$. To provide a further insight into the North Area temperature, one needs to underline that the difference between the maximum and minimum temperature in April 2016 reached $34^{\circ} \mathrm{C}$. The average temperature fluctuation registered in the southern stations of the shelter show higher records if compared with the northern data. Our climate map suggests an area of higher variation in the South-East corner of the shelter $\left(20-22^{\circ} \mathrm{C}\right)$. Medium value thermal excursions are more likely to happen in the center and decrease toward the North, where lower fluctuations were registered in the North-West corner $\left(16.6-17.7^{\circ} \mathrm{C}\right)$ (Fig. 2). A difference of more than $2^{\circ} \mathrm{C}$ is registered between the logger on the floor inside Building 5 (\#707047) and the one on top of the north wall (\#748517). Deeper buildings present lower thermal excursion, while the architectures closer to the surface are more subject to temperature fluctuation [45]. B5 was excavated in 1998 and its floor level remains 3.5-4.5 meters below the ground level. 


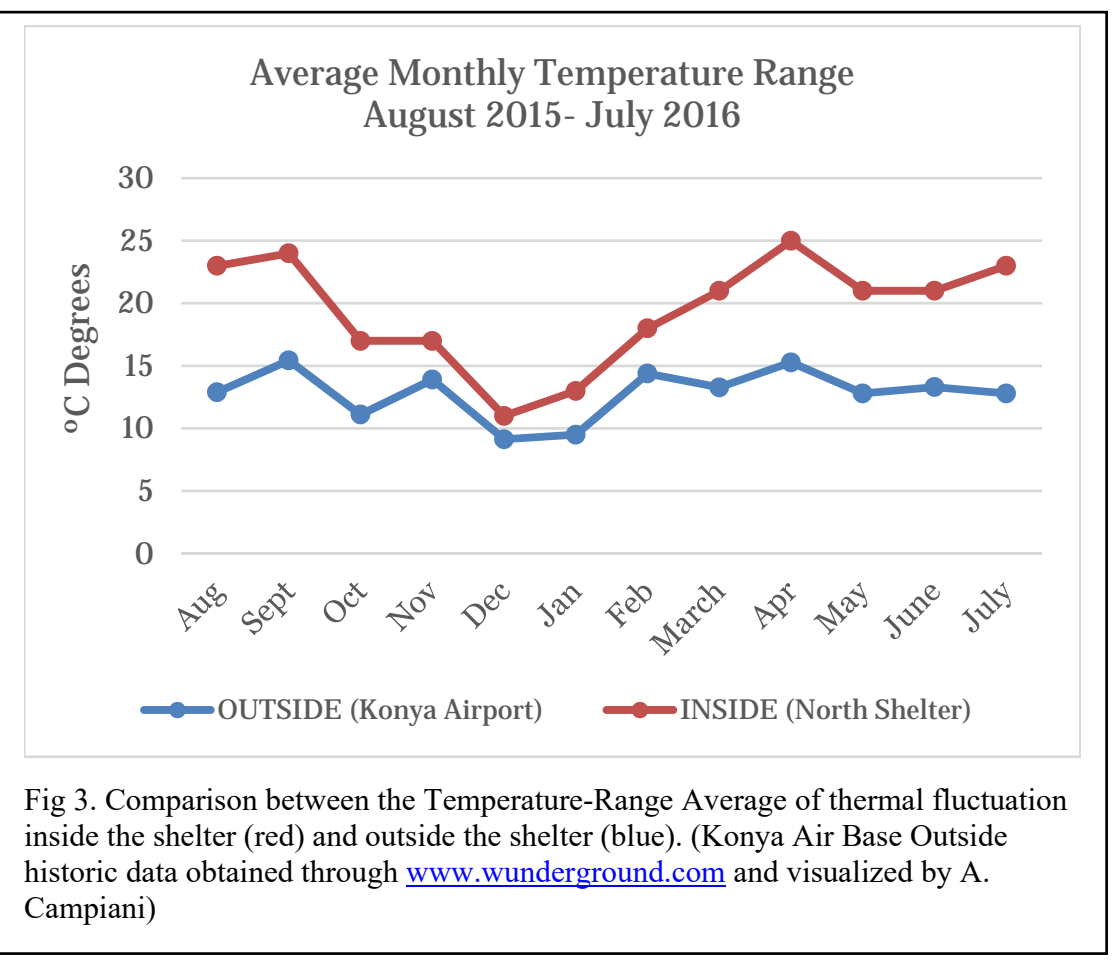

Weather conditions for the Konya plain for the same historic period were also analyzed and compared with our information. The data show that outside the shelter the average range temperature is $13^{\circ} \mathrm{C}$, while the temperature registered for July $31^{\text {st }}$ is $32^{\circ}$ $\mathrm{C}-\mathrm{a} 20^{\circ} \mathrm{C}$ difference between inside and outside [46]. The minimum temperature, however, is not so striking, 2 ${ }^{\circ} \mathrm{C}$ warmer inside the shelter than outside. When comparing the average thermal excursion, it is evident how in the hottest months the variance is accentuated, while in winter it decreases (Fig. 3). Such a difference is certainly related with inadequate UV radiation protection provided by the polycarbonate covering the shelter's roof that contributes to increase temperature variation in the dry hot summers and foster other adverse micro-climatic conditions in other seasons. In addition to dramatic seasonal shifts, the area around the site is a heavily farmed agricultural area, as such water demands in the region have caused the water table beneath the site to dramatically drop since excavations began 25 years ago. It is our hypothesis the dropping water table exacerbates the deterioration through destabilization and wicking, but currently we do not have enough data to confirm the effect of this phenomenon on the archaeology.

Relative humidity is a key aspect for conservation of earthen architecture, for this reason we suggest an estimation of its impact in the North Area by using the available data of the three stations for the period of this study (Fig. 4). 
At Çatalhöyük, soluble salts included in the mud-brick deliquesce starting at about $65 \% \mathrm{RH}$; below this percentage the salts recrystallize and fluoresce. Thus anytime \% RH goes above and then below the deliquescence point, one can expect material loss and erosion to occur. Alternatively, when the percentage of relative humidity drops below $20 \% \mathrm{RH}$, the mud-brick begins to desiccate and plaster delamination and material loss occur. For instance, from September 2015 through June 2016, the maximum \% RH recorded each day was above the deliquesce risk range of $65 \% \mathrm{RH}$, having the most transitional phases in December and January. In contrast, in August and September 2015 the daily \% RH was almost entirely below the desiccation risk range of $20 \%$. The salts identified at Çatalhöyük include: Sodium Chloride $(\mathrm{NaCl})$, Potassium Chloride $(\mathrm{KCl})$, Sodium Nitrate $\left(\mathrm{NaNO}_{3}\right)$, Potassium Nitrate $\left(\mathrm{KNO}_{3}\right)$, potassium magnesium chloride $\left(\mathrm{KMgCl}_{3} \cdot 6\left(\mathrm{H}_{2} \mathrm{O}\right)\right)$, Calcium Sulfate $\left(\mathrm{CaSO}_{4}\right)$, and Sodium Sulfate $\left(\mathrm{Na}_{2} \mathrm{SO}_{4}\right)$.

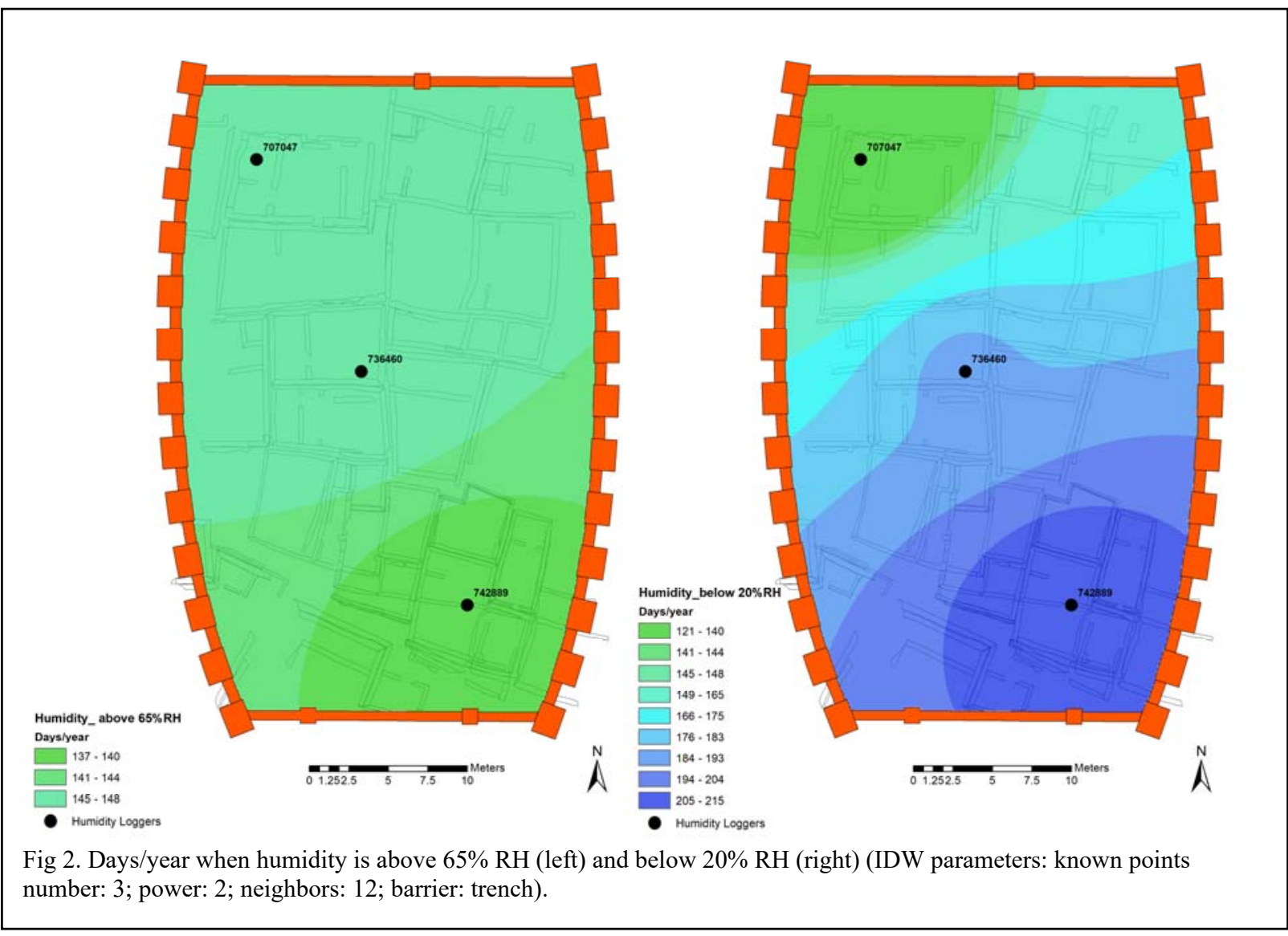

To analyze the potential impact of frequent fluctuations in relative humidity on the earthen architecture, we calculated how many days a year humidity reached the critical values $(>65 \% \mathrm{RH}$ or $<20 \% \mathrm{RH})$ and provided an approximation on the $\% \mathrm{RH}$ variation throughout the shelter. The spatial patterns of \% RH 
suggested by the interpolation, conform to the expected inverse relationship between temperature and humidity. The central section of the North Area, with a tendency toward the North-West corner, reaches the risk range of $65 \% \mathrm{RH}$ more than 147 days each year. The situation is inverted when we take into consideration the minimum \% RH value. Relative humidity variation below $20 \%$ can happen up to 215 days/year, against a maximum value of 148 days/year above the $65 \% \mathrm{RH}$ threshold. The buildings on the North-West corner of the shelter mostly experience this low days-count RH variation, and a lower range of temperature fluctuation $\left(16.69-18.26^{\circ} \mathrm{C}\right)$. On the contrary, our analysis suggests that from the center toward the South-East section of the North Area there is a tendency to lower humidity percentage and higher temperature (Fig. 4). The inverse environmental conditions at the northern and southern ends of the shelter highlight the areas where deterioration is most likely to occur. While the conditions in the central part of the shelter fluctuate, there is generally greater stability.

When dealing with conservation issues in earthen architecture, it is important to consider both temperature and relative humidity and their inverse relationship; for example, even dry air can have a high degree of relative humidity in low temperatures [47, p. 65]. For this reason, we combined temperature and relative humidity data together to create an environmental heritage risk value that estimates the threat to earthen architecture [38], [48]. For temperature, we computed how many days a month there is a fluctuation bigger than the average value plus its standard deviation. Because the three datasets (days with extreme temperature fluctuation, days with high $\mathrm{RH}$, days with low $\mathrm{RH}$ ) are different scales, we normalize the data to be able to examine what areas have more extreme values of different criteria. These normalized Z-scores can be averaged at each position, wherein an "average point" that saw average numbers of extremely fluctuating temperatures, days with high RH, and days of low RH would have a value of 0 , and positive values mean that a point experienced these damaging environmental traits at higher than average rates. This result is an absolute, centered, and normalized risk value given the three parameters, $\% \mathrm{RH}$ above $65, \% \mathrm{RH}$ below 20 , and days with a temperature fluctuation $>$ average +1 standard deviation, where all parameters are equally weighted. 
The interpolation identifies the areas of higher risk in the North-East corner of the shelter, moving toward the center and in its lower sector, with a rate of more than $48 \%$ (Fig. 5). From the North-West corner to

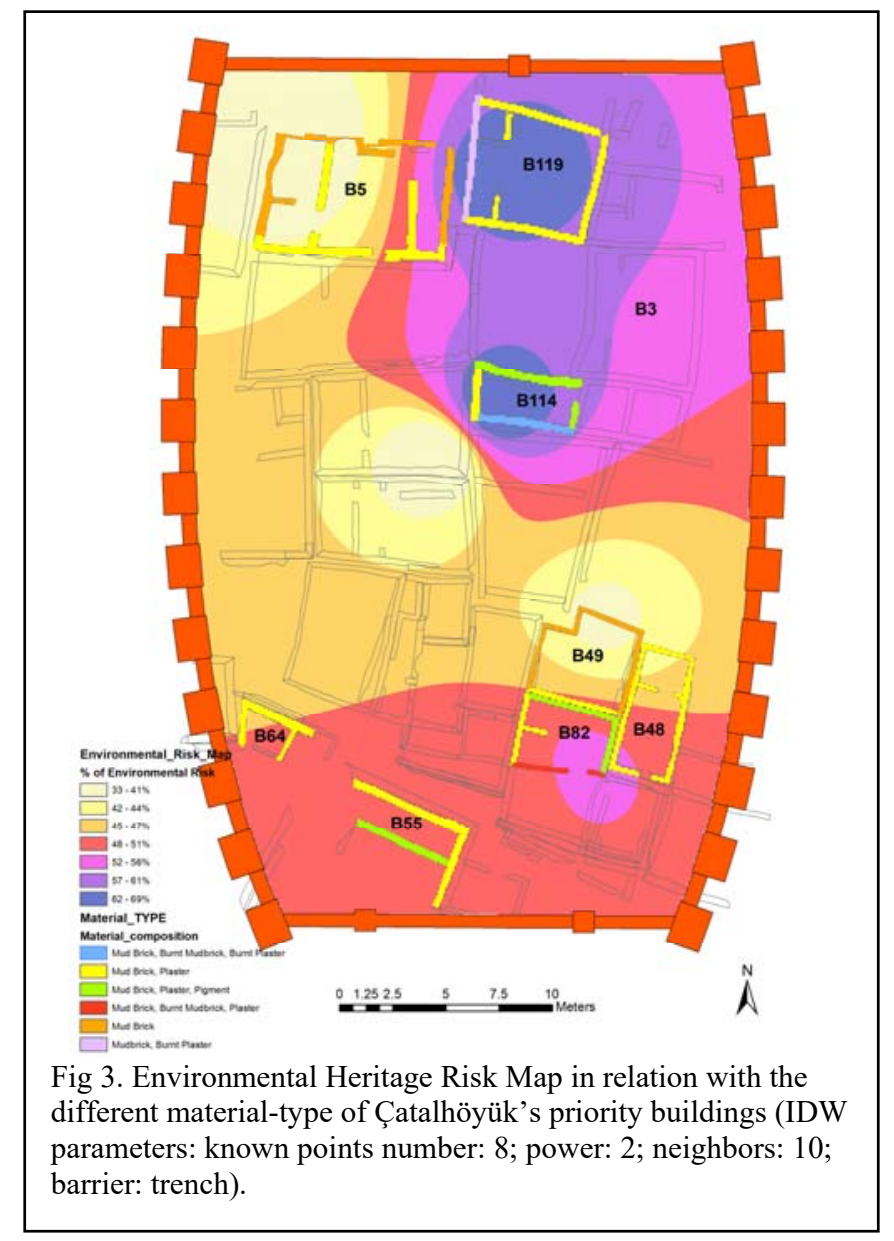

the central area the risk has a smaller impact (between 33-47\%). While the North-East corner of the shelter and its southern end are prone to suffer from great overall climatic instability, the North-West and central area deterioration can be more likely related to the impact of higher moisture levels. Building deterioration can be related to the features' different composition: walls constituted of mud-brick without any plastering or burnt modification generally correspond to the low environmental risk areas (Fig. 5).

It should be noted that Building 3, in the East northern area matches with a high environmental risk zone: it was excavated between 1997-2003 and its walls are currently almost completely eroded, as it periodically floods during the wet fall and winter months.

\subsection{Qualitative vulnerability assessment}

In 2015 and 2017 the Conservation Team performed an in-depth qualitative assessment of the state of preservation of buildings and features of Çatalhöyük. The team evaluated the vulnerability of mud-brick walls on-site, considering the decay caused by: erosion, undercutting, fragmentation, and delamination. Additionally, they look for the presence of deterioration agents such as organic matter, vegetation, insects, and efflorescent salts. This was also an opportunity to assess the effectiveness of previous conservation interventions. Each feature on open-display was examined and photographed. The results were tabulated and images evaluated against the decay baseline maps created in the 2014 season. Overall features tended to score similarly from 2015 to 2017, in instances where there were large discrepancies the area was further investigated and treated as necessary. An absolute damage value was assigned to all of the deterioration variables and a risk threshold was established as $\geq 12$ on a total overall of 20 points. Typically, features with five or more patterns of deterioration scored above a 12 . The greatest limitation 


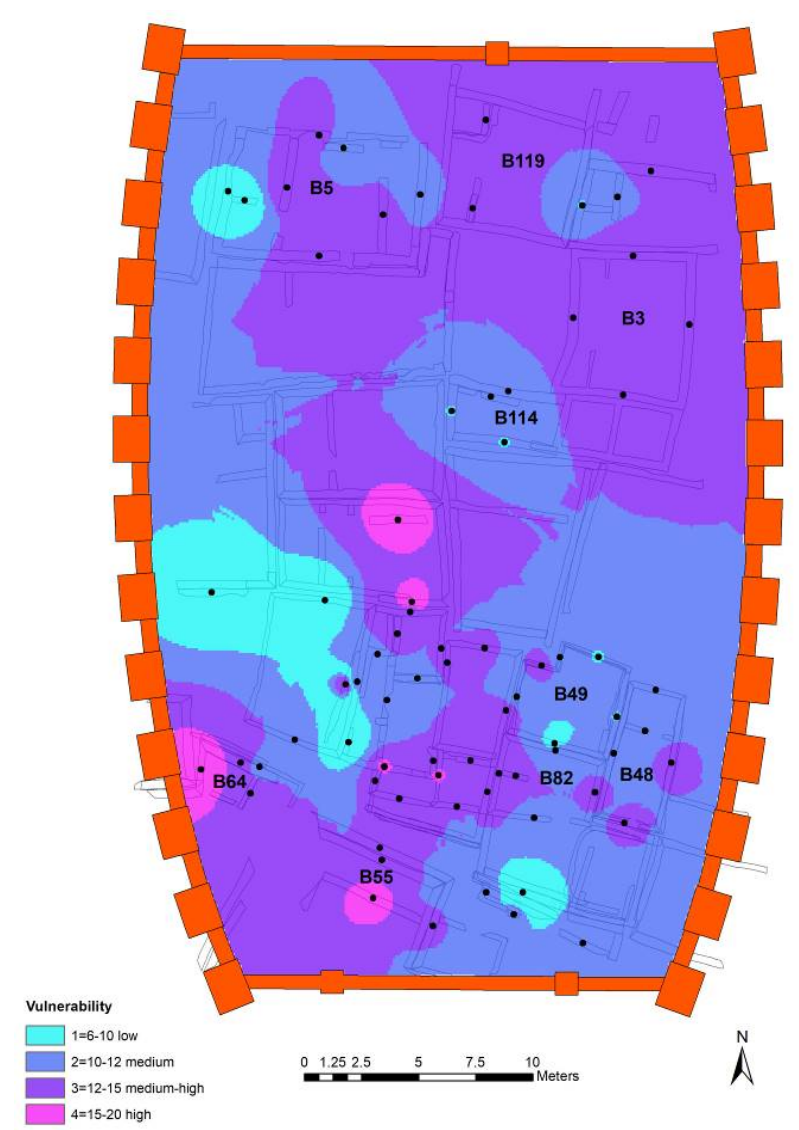

Fig 4. Vulnerability map overlay, 2015-2017 (IDW parameters: known points number: 77; power: 2; neighbors: 10; barrier: trench), showing features' centroids. of this methodology is subjectivity, particularly as there is very little team continuity each year- subsequently the survey is conventionalized with most categories being either present/not-present, or a severity rating between 1-4 (negligible to very severe).

Starting from previous examples of risk maps for cultural heritage [49]-[53], we converted the observational data into a vulnerability map in order to relate trends in observed decay to the environmental risks modeled by temperature and relative humidity. Features' centroids were calculated for each surveyed wall, for a total of 77 values, and associated with their overall risk assessment. The overlay of the 2015 and 2017 maps shows that the more vulnerable areas have a tendency to spread from North-East and pass

through the center of the shelter toward the South-West corner (Fig. 6). It is interesting to notice that the approximation presented by our spatial analysis to the concurrent conditions that affect earthen architecture at Çatalhöyük is able to suggest a direct correspondence between the qualitative data and the vulnerable areas they identify, and the environmental risk areas (Fig. 5 and Fig. 6).

\subsection{Features comparison}

To infer the amount of damage the mud-brick features suffer through time, we compared 39 walls belonging to our eight priority buildings scanned yearly in the North Area in the period 2012-2017. The related point clouds were segmented and aligned in CloudCompare into a series of historic data. The reference for the alignment was chosen in the 2014-point cloud, being the 2012 and 2013 often scattered and thus less reliable for point comparison. Once aligned, the surface change among different instances of the same feature was computed with a millimeter-level accuracy using the Multiscale Model to Model Cloud Comparison (M3C2) method [54], [55]. 


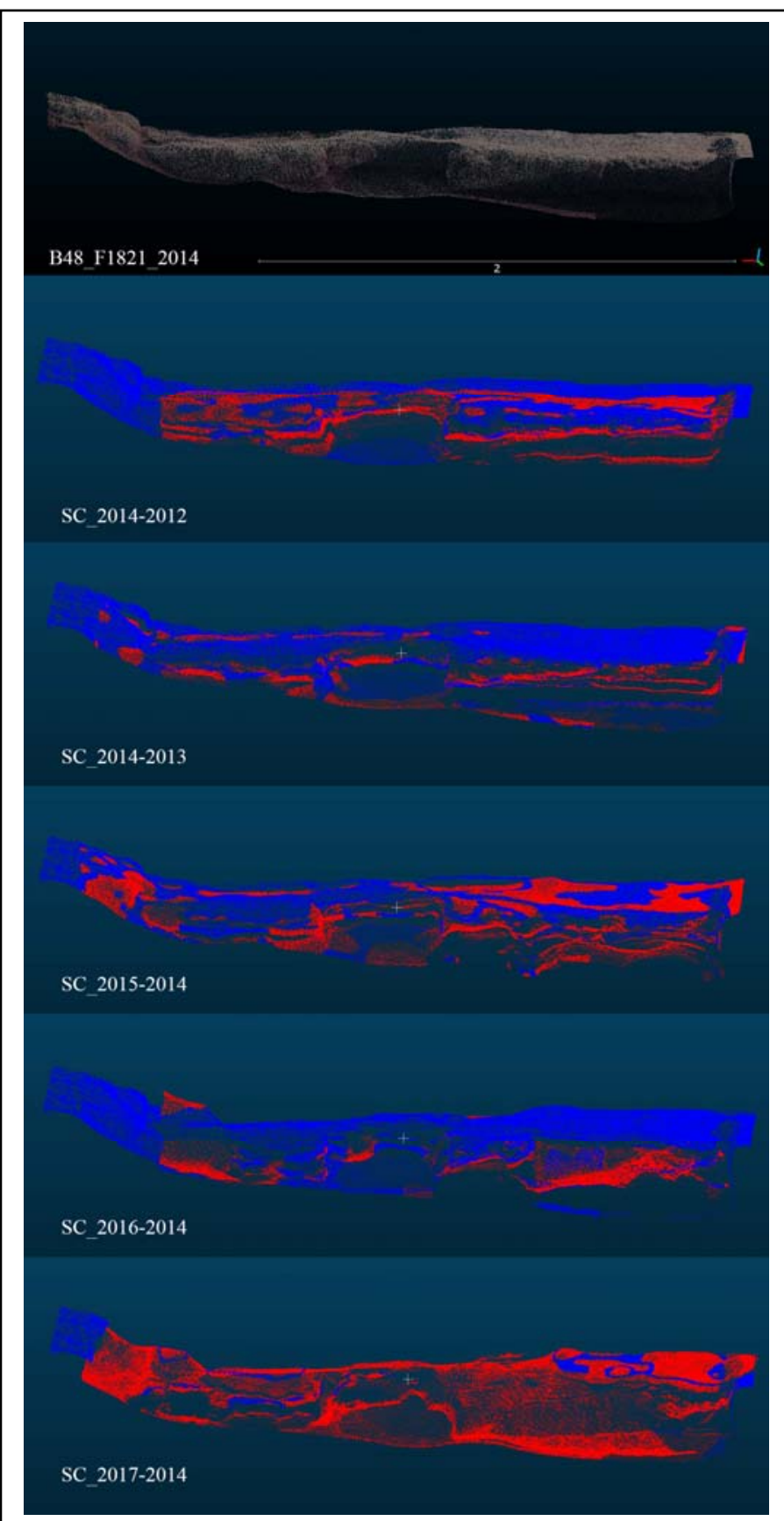

Fig 5. Building 48, Point cloud of Feature 1821 in 2014 (above) and the variation of Significant Change areas as outlined in CloudCompare, from 2012 to 2017 (below). Red points show change while blue points indicate no significant change.
M3C2 considers a subset of points, defined core points, that can be automatically subsampled and are used to compute and visualize the surface affected by significant change (Fig. 7) [19]. Using a MATLAB routine developed in our laboratory [56], we averaged features' distance into a single value that expresses the deterioration of a wall when compared to its 2014 reference point cloud. This value, related to the feature's area ( $\%$ of material loss) has been imported into the GIS where the loss can be spatialized and the succession of year-maps can express the occurrence of the variation. When comparing the trend of material loss throughout the years with the conservation actions implemented for a single feature, our quantification can be used to evaluate the success of in situ interventions.

The Conservation Team started to systematically record conservation actions on-site in 2015. Previous restoration efforts were assessed through qualitative survey and features' observation. By analyzing the variation of values obtained through $\mathrm{M} 3 \mathrm{C} 2$ point cloud comparison prior to 2015 , we can thus infer whether previous restorations took place. For instance, in the case of the wall features of Building 48 (Fig. 8), a

decreasing in $\%$ of material loss detected in 2013 suggests that successful conservation interventions for all of the features occurred in 2012 (Table 1). Similarly, significant reduction of \% of material loss 
documented in 2016 in the same building, points out that successful interventions were undertaken also in 2015. Additionally, our data suggest that - except for Feature 1824 - all walls have suffered material loss between 2016 and 2017, with a dramatic loss documented in Feature 1824, the South perimeter wall of Building 48.

Open access to the raw and processed data presented in this paper and their related metadata, is guaranteed through a partnership with the University of California San Diego-Center for CyberArchaeology and Sustainability [57].

\begin{tabular}{|c|c|c|c|c|c|c|c|c|c|c|c|c|c|}
\hline \multirow{2}{*}{ Building } & \multirow{2}{*}{ Feature } & \multirow[t]{2}{*}{$\begin{array}{c}\text { Core } \\
\text { Points }\end{array}$} & \multirow[t]{2}{*}{$\begin{array}{c}\text { Area } \\
\mathrm{m} 2\end{array}$} & \multicolumn{5}{|c|}{$\begin{array}{l}\text { Percentage Significant Change (significant change } \\
\text { value/core points number) }\end{array}$} & \multicolumn{5}{|c|}{ Percentage of Material Loss (Average value/Feature Area) } \\
\hline & & & & $14 \_12 \%$ & $14 \_13 \%$ & $14 \_15 \%$ & $14 \_16 \%$ & $14 \_17 \%$ & \%change12 & \%change13 & \%change15 & \%change16 & $\%$ change17 \\
\hline 48 & 1818 & 147289 & 1.03 & 26.79 & 23.67 & 58.31 & 23.50 & 44.18 & 0.04 & 0.05 & 1.92 & 0.39 & 1.70 \\
\hline 48 & 1820 & 263317 & 1.68 & 75.38 & 34.32 & 64.13 & 32.56 & 55.96 & 0.28 & 0.08 & 0.67 & 0.03 & 1.20 \\
\hline 48 & 1821 & 121951 & 0.48 & 38.01 & 22.50 & 53.25 & 21.99 & 87.15 & 3.57 & 0.50 & 1.61 & $\mathrm{NA}$ & 13.87 \\
\hline 48 & 1824 & 86029 & 0.80 & 44.69 & 53.24 & 4.49 & 76.88 & 73.62 & 0.19 & 0.52 & 0.31 & 1.30 & 1.11 \\
\hline
\end{tabular}

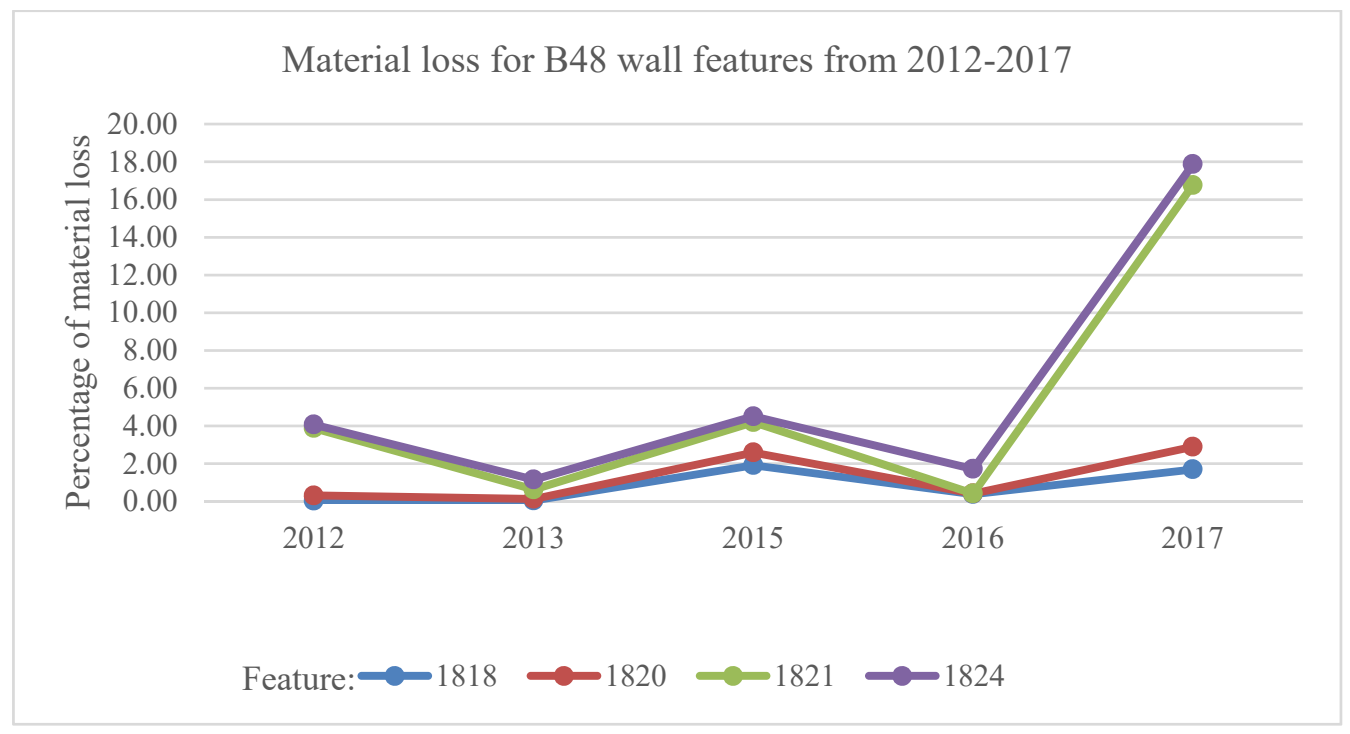

Fig 6. Material loss for Building 48 wall features from 2012 to 2017.

\section{Results and discussion}

Before the construction of the North shelter, thanks to the analyses conducted between 1998-2002 in Building 5, Matero and Moss [6, p. 218] observed that walls protected by sun- and wind-screening temporary shelters were presenting lower temperature and desiccation with respect to the unprotected 
features. After measuring moisture content in plaster walls, they concluded that soluble salts were causing overall moisture content at or near the surface causing flaking, delamination and detachment [6, p. 221]. Even if it prevents the erosion caused by wind, our analyses have highlighted how the North Area shelter fosters adverse micro-climatic conditions. The dramatic undercutting process assessed by Lingle on-site can probably be a consequence of the same shelter-associated environs [58, p. 2].

To get deeper into the analysis of deterioration and conservation associated with inside environmental condition, we can consider the period 2015-2017. It corresponds to our 2015-2016 temperature and

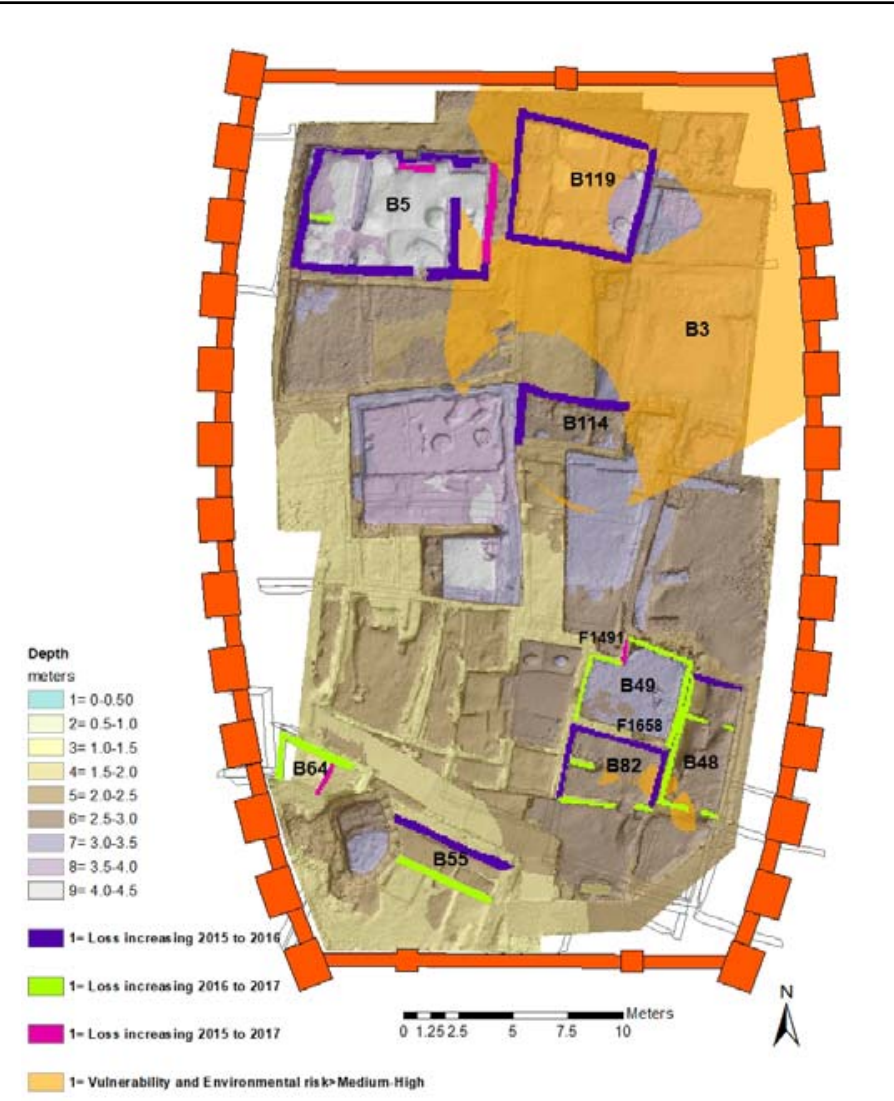

Fig 7. Area of medium to high risk (orange) obtained from the reclassification and sum of the vulnerability map and the environmental risk map, in relation with the percentage of Material Loss from 2015 to 2017. humidity data collection as well as it overlaps with the 2015 vulnerability assessment carried out by the Conservation Team. Italso refers to actions and conditions between 2016 and 2017. In GIS, we reclassified the vulnerability map and the environmental risk map into four categories of risk (1=low; 2=medium; 3=medium-high; 4=high) and we highlighted the area of medium to high risk, as it is more significant to emphasize the dual nature of our dataset and the way it was utilized to monitor earthen architecture (Fig. 9). Furthermore, the operations performed with raster calculator show where material loss increments from 2015 to 2016 , from 2016 to 2017 and the overall of these two operations, from 2015 to 2017. The zone of medium to high risk primarily involves the North-East corner of the shelter, where B119 and B3 are located; it moves toward the center of the shelter and B114, with some scattered areas on the southern corner of B82 and B48 to the East.

Our map shows how from 2015 to 2016 material loss is documented throughout all the shelter, being B5 and B119 affected features. It is important to notice that B119 and B3 are characterized by a depth of 3 to 
4.5 meters. This condition is more likely to foster deterioration: even in sectors of lower environmental risk, like the North-West corner, we observe diffuse material loss and high moisture content (Fig. 9).

Between 2016 and 2017 the increasing in material loss is documented almost entirely in the south-eastern priority buildings, located at the edge of high and low environmental risk area of the site. Specifically, the deterioration of B49 mud-brick features increased from 2016 to 2017, most dramatically for the northern wall Feature 1491. On the contrary, the southern wall, F1658, composed of plastered mud-brick seems

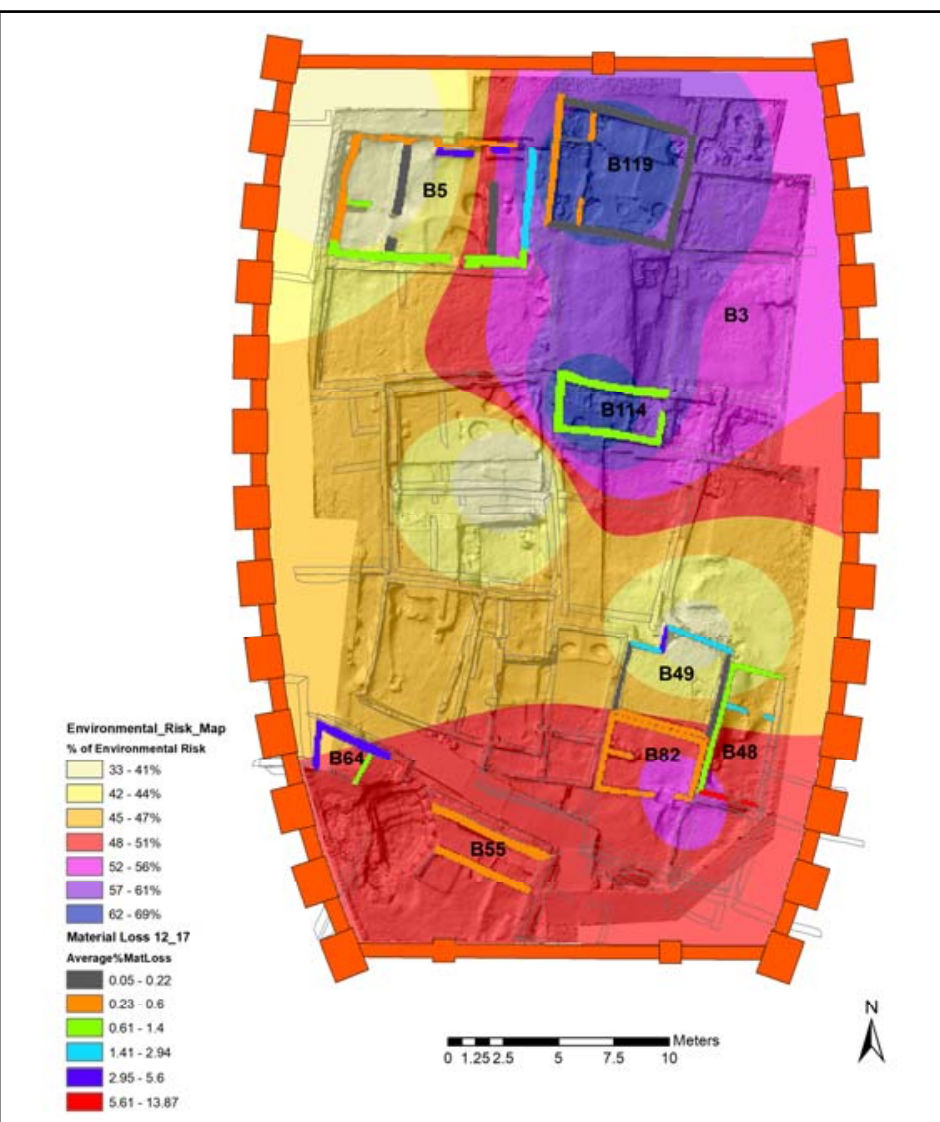

Fig 8. Overall Percentage of Material Loss in relation to the Environmental Risk estimation. not to be interested by this phenomenon during the same period of time. Again, a variable to take into consideration that can foster material loss is the depth of the building, which varies from 2.5 to 3.5 meters.

Between 2012 and 2017, the high rate of material loss $(>1.41 \%)$ can be observed in low and high environmental risk areas (Fig. 10). It can be noticed a tendency of deterioration in deeper buildings that have been excavated from 1998 to 2006 and, thus, present longer exposure to the environs as it is the case of B5, B49, B64 and B48. Regardless of walls' orientation, the features where more material loss happened through time are composed by mud-brick and plastered mud-brick.

The maps overlay stresses several causes and trends: environmental risk is a major cause of instability throughout the shelter, nonetheless it has to be associated with buildings' depth and features' composition in order to understand how the combination of these variables fosters material loss and promote deterioration. For example, Buildings 5 in the north sector of the shelter was excavated in 1998, prior to the shelter construction and it is subject to a constant material loss. In this building, all kind of 
deterioration conditions have been observed. It is located in a fringe zone between low and highenvironmental risk: the environmental condition, in association with the depth of the excavation and, thus, of features' contact with the ground $(>3.50 \mathrm{~m})$ might promote detachment. The walls predominantly suffer from undercutting, correlating to high relative humidity fostering salt deliquescence and moisture formation inside the mud-brick walls and wicking from subterranean contaminates.

\section{Conclusion}

The combination of environmental spatial analyses and 3-D data on material loss creates a productive tool for archaeological heritage monitoring. In particular, our analysis considers the concurrence of several factor in the implementation of deterioration conditions of wall features through time. We studied environmental data obtained for the Çatalhöyük North Area between 2015 and 2016 via TinyTag data loggers, which measured temperature and humidity under the shelter. For archaeologists working under the shelter during the summer experiencing environmentally oppressive working conditions [31, p. 160], the mapping of this information draws attention on how dramatic the situation can be. Here, the temperature can reach $52{ }^{\circ} \mathrm{C}$ degree with a difference of more than $20{ }^{\circ} \mathrm{C}$ degree relative to the outside temperature. Humidity also plays an important role in damage to the mud-brick walls: days in which salt deliquescence and recrystallizations occur during a year are extremely frequent in the Çatalhöyük North Area.

This project and collaboration have yielded surprising results for the site's conservators. While much of the conservation interventions have focused on the northwest corner of the shelter, it has suggested that conservation works need to be more evenly dispersed to the southern end. The vulnerability assessment provided by the conservators about their interventions has complemented the research at a shelter level by outlining features and areas more prone to deterioration agents. The direct benefits of this study for conservators at Çatalhöyük include: providing a quantitative overview of deterioration at the site, shaping informed conservation practice, aiding in the implementation of proactive treatments opposed to reactionary ones, and creating an informed base for new conservators coming to work at the site.

At the feature level, we have measured the material loss affecting eight priority buildings through time with a novel technique based on the comparison of available 3-D data. The material loss calculation has also allowed us to evaluate the efficacy of the materials employed by conservators, and to estimate their life-span. Our analysis also emphasizes that semi-automated comparison of TLS data can be exploited to 
identify the causes of mud-brick decay. When transferred to the GIS platform the value obtained thanks to a MATLAB routine we developed, can be associated with other deterioration risk factors.

Our study suggests that the monitoring of earthen sites can be improved when using several scales of spatial analysis (e.g. area-wide, building-level, feature-level), and when the relation between the concurrent conditions that elicit deterioration is explored. Our research has highlighted the importance of assessing the environmental conditions at an intra-site level to understand the distribution and propagation of temperature and humidity, which we were able to partially estimate with GIS due to the limited number of monitoring stations. For this reason, this investigation constituted the occasion to reflect on effective practices for the monitoring of earthen architecture sites, where data loggers represent a fundamental component to understand wet/dry cycles in mud-bricks and, thus, should be included in the budget allocated for conservation. Our spatial analytical models represent a first step toward the systematic qualitative and quantitative monitoring of Çatalhöyük earthen architecture.

Like any earthen site there is no perfect conservation solution, however, with the aid of 3-D data and GIS monitoring, conservators at Çatalhöyük can now select more effective polymers (when needed), and otherwise focus on traditional earth-based repairs because they are proving to be a greater long-term strategy. More broadly, we believe that the workflow we implemented is applicable to a variety of heritage sites, including but not limited to archaeological sites with earthen architecture inside and outside the Near East.

\section{Acknowledgements}

We would like to thank all of the Çatalhöyük Conservation Team members Phil Parkes, Jerrod Seifert, and Çatalhöyük Research Project team members Justine Issavi, Dominik Lukas and Tolga Bayram for contributing to outlining the best practice methodology discussed in this article. Camilla Mazzuccato for providing the geodatabase this research builds upon. We thank HIVE Lab students Estrella García, John Flynn, Tristan Young, Moataz Dahabra, Christopher Reps and Jad Aboulhosn for contributing to our data processing, analysis and software development. We are particularly thankful to Elisabetta Campiani, Esteban Mirón Marván, Lorenzo Zurla, Nicholas Tripcevich, Jesse Wolfhagen and Erin Hestir for providing invaluable suggestions on how to enhance our analyses, to Gina Palefsky for proof reading the article and Ho Jung Yoo and Ryan Johnson for helping curate and publish the data.

\section{Funding}


This work was supported by an Archaeological Institute of America Site Preservation Grant and by a University of California President's Catalyst Research Award (Grant ID: CA-16-376911).

Funding sources had no involvement in the study design, data collection, analysis, interpretation, not in the decision to submit the article for publication.

\section{Declaration of Interests: none}

\section{Bibliography}

[1] F. Matero, "Mud Brick Metaphysics and the Preservation of Earthen Ruins," Conservation and Management of Archaeological Sites, vol. 17, no. 3, pp. 209-223, Jul. 2015.

[2] C. N. Cancino, "Recording and Documentation of Earthen Architecture," in Terra Literature Review: An Overview of Research in Earthen Architecture Conservation, The Getty Conservation Institute., E. Avrami, H. Guillaud, and M. Hardy, Eds. Los Angeles, 2008, pp. 32-44.

[3] D. Friesem, E. Boaretto, A. Eliyahu Behar, and R. Shahack-Gross, "Degradation of mud brick houses in an arid environment: A geoarchaeological model," Journal of Archaeological Science, vol. 38, pp. 1135-1147, May 2011.

[4] L. Rainer, "Deterioration and Pathology of Earthen Architecture," in Terra Literature Review: An Overview of Research in Earthen Architecture Conservation, Los Angeles: The Getty Conservation Institute, 2008, pp. 45-61.

[5] F. Uviña Contreras, "Adobe architecture conservation handbook," 1998.

[6] F. Matero and E. Moss, "Temporary site protection for earthen walls and murals at Çatalhöyük, Turkey," Conservation and Management of Archaeological Sites, vol. 6, no. 3-4, pp. 213-227, Jan. 2004.

[7] L. Bornaz, F. Rinaudo, and P. Ardissone, "3D High accuracy survey and modelling for Cultural Heritage Documentation and Restoration," in Future technologies to empower heritage professionals, Brighton, 2007, pp. 19-23.

[8] J. De Reu, P. De Smedt, D. Herremans, M. Van Meirvenne, P. Laloo, and W. De Clercq, “On introducing an image-based 3D reconstruction method in archaeological excavation practice," Journal of Archaeological Science, vol. 41, pp. 251-262, Jan. 2014.

[9] J. De Reu et al., "Towards a three-dimensional cost-effective registration of the archaeological heritage," Journal of Archaeological Science, vol. 40, no. 2, pp. 1108-1121, Feb. 2013.

[10] T. E. Levy, "Cyber-Archaeology and World Cultural Heritage: Insights from the Holy Land," Bulletin of the American Academy of Arts \& Sciences, vol. 66, pp. 26-33, 2013.

[11] M. Lezzerini et al., "Cultural Heritage Documentation and Conservation: Three-Dimensional (3D) Laser Scanning and Geographical Information System (GIS) Techniques for Thematic Mapping of Facade Stonework of St. Nicholas Church (Pisa, Italy)," International Journal of Architectural Heritage, vol. 10, no. 1, pp. 9-19, Jan. 2016.

[12] M. J. Olsen, F. Kuester, B. J. Chang, and T. C. Hutchinson, "Terrestrial Laser Scanning-Based Structural Damage Assessment," Journal of Computing in Civil Engineering, vol. 24, no. 3, pp. 264-272, May 2010.

[13] G. Landeschi, B. Nilsson, and N. Dell’Unto, "Assessing the damage of an archaeological site: New contributions from the combination of image-based 3D modelling techniques and GIS," Journal of Archaeological Science: Reports, vol. 10, pp. 431-440, 2016.

[14] O. Risbøl, C. Briese, M. Doneus, and A. Nesbakken, "Monitoring cultural heritage by comparing DEMs derived from historical aerial photographs and airborne laser scanning," Journal of Cultural Heritage, vol. 16, no. 2, pp. 202-209, Mar. 2015. 
[15] S. H. Savage, A. Johnson, and T. E. Levy, "TerraWatchers, Crowdsourcing, and At-Risk World Heritage in the Middle East," in Heritage and Archaeology in the Digital Age, Springer, Cham, 2017, pp. 67-77.

[16] H. Barnard, W. Z. Wendrich, A. Winkels, J. E. M. F. Bos, B. L. Simpson, and R. T. J. Cappers, "The preservation of exposed mudbrick architecture in Karanis (Kom Aushim), Egypt," Journal of Field Archaeology, vol. 41, no. 1, pp. 84-100, Jan. 2016.

[17] J. Barton, "3D Laser Scanning and the Conservation of Earthen Architecture: A Case Study at the UNESCO World Heritage Site Merv, Turkmenistan," World Archaeology, vol. 41, no. 3, 2009.

[18] Y. Fujii, E. Fodde, K. Watanabe, and K. Murakami, "Digital photogrammetry for the documentation of structural damage in earthen archaeological sites: The case of Ajina Tepa, Tajikistan," Engineering Geology, vol. 105, no. 1, pp. 124-133, Apr. 2009.

[19] A. Lingle, N. Lercari, and A. Campiani, "Terrestrial Laser Scanning and Conservation of at-risk World Heritage," presented at the SAA 83rd Annual Meeting, Washington, DC, 2018.

[20] A. Berggren et al., "Revisiting reflexive archaeology at Çatalhöyük: integrating digital and 3D technologies at the trowel's edge," Antiquity, vol. 89, no. 344, pp. 433-448, 2015.

[21] I. Hodder, Towards Reflexive Method in Archaeology: The Example at Çatalhöyük. McDonald Institute for Archaeological Research and British Institute at Ankara, Monograph 28, London, 2000.

[22] J. S. Taylor, "Making time for space at Çatalhöyük," The University of York, York, UK, 2016.

[23] D. Lees, "Geomatics," Çatalhöyük Archive Report, 2003.

[24] M. Forte, N. Dell'Unto, K. Jonsson, and N. Lercari, "Interpretation Process at Çatalhöyük using 3D," in Assembling Çatalhöyük, vol. 1, Ian Hodder and Arkadiusz Marciniak, Eds. New York: Routledge, 2015, pp. 43-57.

[25] M. Forte, N. Dell'Unto, J. Issavi, L. Onsurez, and N. Lercari, "3D archaeology at Çatalhöyük," International Journal of Heritage in the Digital Era, vol. 1, no. 3, pp. 351-378, 2012.

[26] N. Lercari, E. Shiferaw, M. Forte, and R. Kopper, "Immersive Visualization and Curation of Archaeological Heritage Data: Çatalhöyük and the Dig@IT App,” J Archaeol Method Theory, pp. 1-25, Jun. 2017.

[27] N. Lercari, A. Lingle, and O. Umurham, "Çatalhöyük Digital Preservation Project," Çatalhöyük Archive Report, 2016.

[28] N. Lercari and A. Lingle, "Çatalhöyük Digital Preservation Project," Çatalhöyük Archive Report, 2015.

[29] A. Bayliss, F. Brock, S. Farid, I. Hodder, J. Southon, and R. E. Taylor, "Getting to the Bottom of It All: A Bayesian Approach to Dating the Start of Çatalhöyük," J World Prehist, vol. 28, no. 1, pp. 126, Mar. 2015.

[30] A. Marciniak et al., "Fragmenting times: interpreting a Bayesian chronology for the Late Neolithic occupation of Çatalhöyük East, Turkey," Antiquity, vol. 89, no. 343, pp. 154-176, Feb. 2015.

[31] A. Lingle, "Conservation," Çatalhöyük Archive Report, 2014.

[32] A. Setianto and T. Triandini, "Comparison of Kriging and Inverse Distance Weighted (IDW) interpolation methods in lineament extraction and analysis," J. SE Asian Appl. Geol., vol. 5, no. 1, pp. 21-29, Jun. 2013.

[33] J. Li and A. D. Heap, A Review of Spatial Interpolation Methods for Environmental Scientists, Geoscience Australia, vol. 23. 2008.

[34] M. N. Ikechukwu, E. Ebinne, U. Idorenyin, and N. I. Raphael, “Accuracy Assessment and Comparative Analysis of IDW, Spline and Kriging in Spatial Interpolation of Landform (Topography): An Experimental Study," Journal of Geographic Information System, vol. 09, no. 03, pp. 354-371, 2017.

[35] R. Bakış, Y. Bayazıt, H. Uyguçgil, and C. Koç, "Mapping of Precipitation, Temperature and Evaporation Distributions in the Porsuk Basin Using Distant Forecasting Methods," Computational Water, Energy, and Environmental Engineering, vol. 06, p. 321, Sep. 2017. 
[36] H. Chai, W. Cheng, C. Zhou, X. Chen, X. Ma, and S. Zhao, "Analysis and comparison of spatial interpolation methods for temperature data in Xinjiang Uygur Autonomous Region, China," Natural Science, vol. 03, no. 12, pp. 999-1010, 2011.

[37] M. Demırcan, İ. Alan, and S. Şensoy, "Increasing resolution of temperature maps by using Geographic Information Systems (GIS) and topography information," EMS Annual Meeting Abstracts, vol. 8, no. EMS2011-182, pp. 1-13, 2011.

[38] P.-S. Wu, C.-M. Hsieh, and M.-F. Hsu, "Using heritage risk maps as an approach to estimating the threat to materials of traditional buildings in Tainan (Taiwan)," Journal of Cultural Heritage, vol. 15, no. 4, pp. 441-447, 2014.

[39] M. Brizzi, S. Court, A. d'Andrea, A. Lastra, and D. Sepio, "3D Laser Scanning as a Tool for Conservation: The Experiences of the Herculaneum Conservation Project," in The 7th International Symposium on Virtual Reality, Archaeology and Cultural Heritage VAST, 2006, p. 7.

[40] N. Lercari, "Terrestrial Laser Scanning in the Age of Sensing," in Digital Methods and Remote Sensing in Archaeology, M. Forte and S. Campana, Eds. Springer, Cham, 2016, pp. 3-33.

[41] P. M. Lerones, D. O. Vélez, F. G. Rojo, J. Gómez-García-Bermejo, and E. Z. Casanova, "Moisture detection in heritage buildings by 3D laser scanning," Studies in Conservation, vol. 61, no. sup1, pp. 46-54, Mar. 2016.

[42] R. Scopigno, "Sampled 3D models for Cultural Heritage: which uses beyond visualization?," Virtual Archaeology Review, vol. 3, no. 5, p. 109, May 2012.

[43] D. Lague, N. Brodu, and J. Leroux, "Accurate 3D comparison of complex topography with terrestrial laser scanner: Application to the Rangitikei canyon (NZ)," ISPRS journal of photogrammetry and remote sensing, vol. 82, pp. 10-26, 2013.

[44] CloudCompare. (version 2.9). 2018. GPL software. http://www.cloudcompare.org/

[45] G. De Guichen, "L'oggetto interrato, l'oggetto disinterrato," in La Conservazione sullo Scavo Archeologico, N. Stanley-Price, Ed. Roma: CCA-ICCROM, 1986, pp. 25-34.

[46] "Weather History Konya, Turkey Aug2015_July2016." 2018. https://www.wunderground.com

[47] B. V. Ridout, "Moisture Monitoring in Earthen Structures," in Terra Literature Review: An Overview of Research in Earthen Architecture Conservation, E. Avrami, H. Guillaud, and M. Hardy, Eds. Los Angeles: The Getty Conservation Institute, 2008, pp. 62-68.

[48] A. Elfadaly, W. Attia, and R. Lasaponara, "Monitoring the Environmental Risks Around Medinet Habu and Ramesseum Temple at West Luxor, Egypt, Using Remote Sensing and GIS Techniques," J Archaeol Method Theory, vol. 25, no. 2, pp. 587-610, 2018.

[49] G. Accardo, E. Giani, and A. Giovagnoli, "The Risk Map of Italian Cultural Heritage," Journal of Architectural Conservation, vol. 9, no. 2, pp. 41-57, Jan. 2003.

[50] M. Andretta, F. Coppola, A. Modelli, N. Santopuoli, and L. Seccia, "Proposal for a new environmental risk assessment methodology in cultural heritage protection," Journal of Cultural Heritage, vol. 23, pp. 22-32, 2017.

[51] G. Forino, J. MacKee, and J. von Meding, "A proposed assessment index for climate change-related risk for cultural heritage protection in Newcastle (Australia)," International Journal of Disaster Risk Reduction, vol. 19, pp. 235-248, 2016.

[52] P. Ortiz, V. Antunez, J. M. Martín, R. Ortiz, M. A. Vázquez, and E. Galán, “Approach to environmental risk analysis for the main monuments in a historical city," Journal of Cultural Heritage, vol. 15, no. 4, pp. 432-440, 2014.

[53] X. Romão, E. Paupério, and N. Pereira, "A framework for the simplified risk analysis of cultural heritage assets," Journal of Cultural Heritage, vol. 20, pp. 696-708, 2016.

[54] T. Barnhart and B. Crosby, "Comparing Two Methods of Surface Change Detection on an Evolving Thermokarst Using High-Temporal-Frequency Terrestrial Laser Scanning, Selawik River, Alaska," Remote Sensing, vol. 5, no. 6, pp. 2813-2837, 2013.

[55] M. R. James, S. Robson, and M. W. Smith, "3-D uncertainty-based topographic change detection with structure-from-motion photogrammetry: precision maps for ground control and directly 
Campiani et al. 2019 - Author Version

georeferenced surveys," Earth Surface Processes and Landforms, vol. 42, no. 12, pp. 1769-1788, Sep. 2017.

[56] M. Dahabra, C. Reps, and J. Aboulhosn, "M3C2 Material Loss Calculation for MATLAB," 12-Oct2018. [Online]. Available: https://github.com/hivelab1/MaterialLoss. [Accessed: 13-Oct-2018].

[57] A. Campiani et al., "Spatial Analysis and Heritage Conservation: Leveraging 3-D Data and GIS for Monitoring Çatalhöyük Earthen Architecture.” Digital Data Collection, UC San Diego Library Digital Collections, 2018. https://library.ucsd.edu/dc/collection/bb62154893

[58] A. Lingle and N. Lercari, "Çatalhöyük Digital Preservation Project: Pilot program in integrated digital monitoring strategies," in ICOM-CC 18th Triennial Conference, Copenhagen, 2017, pp. 1-8. 